\title{
OVOGENĖSE CHEZ L'ANGUILLE (ANGUILLA ANGUILLA L.) : ULTRASTRUCTURE DE L'OVAIRE A DIFFÉRENTS STADES DE DÉVELOPPEMENT ET IMPLICATION DES LIPOPROTÉINES AU COURS DE LA VITELLOGENĖSE.
}

\author{
E. BURZAWA-GERARD (1), S. BALOCHE (1), J. LELOUP-HATEY (1) \\ F. LE MENN (2), H. MESSAOURI (1), J. NUNEZ-RODRIGUEZ (2), \\ P. PEYON (1) et C. ROGER (1).
}

(1) Laboratoire de Physiologie Générale et Comparée, Muséum National d'Histoire Naturelle, URA 90 CNRS. Evolution des Régulations Endocriniennes, 7 rue Cuvier, 75231 Paris Cedex 05, France.

(2) UA INRA de Biologie de la Reproduction des Poissons, Université de Bordeaux I, 33405 TALENCE, France.

\section{RÉSUMÉ}

Dans les eaux douces, l'anguille est présente à deux stades de développement : le stade jaune où l'animal se nourrit et assure sa croissance et le stade argenté où il jeûne et se prépare à la migration de reproduction. Ce cycle est particulièrement intéressant pour l'étude des régulations hormonales de l'ovogenèse et en particulier celle de la vitellogenèse, étape pendant laquelle l'ovocyte incorpore la vitellogénine pour former le vitellus. Cet article décrit, d'une part, les différents critères de la vitellogenèse disponibles chez l'anguille (caractérisation des lipoprotéines, ultrastructure des ovocytes, teneurs plasmatiques des stéroïdes sexuels et de la vitellogénine, caractérisation des récepteurs hépatiques de l'œestradiol (RE2)) et, d'autre part, l'effet de traitements gonadotropes ou stéroïdiens sur ces critères pour dégager la nature des contrôles endocriniens impliqués au cours de la vitellogenèse. Les lipoprotéines présentes dans le plasma de l'anguille jaune ou argentée sont les VLDL (lipoprotéine de très faible densité) et les HDL (lipoprotéine de haute densité) ; les LDL (lipoprotéine de faible densité) ne sont pas trouvées. Des modifications des apolipoprotéines présentes dans les lipoprotéines de haute densité (HDL) sont observées au cours de l'argenture. Par des traitements à l'œstradiol, les VLDL augmentent considérablement ; il apparaît aussi une classe nouvelle de lipoprotéines, les VHDL (lipoprotéine de très haute densité) ou vitellogénine. L'analyse de l'ultrastructure ovocytaire montre que l'anguille jaune est prévitellogénique en raison de l'absence des structures ovocytaires spécifiques de l'endocytose ; elles sont présentes chez l'anguille argentée qui est donc vitellogénique. In vivo chez l'anguille jaune, après un mois de traitement gonadotrope, une augmentation de l'œstradiol (E2) plasmatique est observée sans apparition de vitellogénine circulante. Toutefois, si les traitements sont prolongés, la vitellogenèse s'amorce. Chez l'anguille argentée, la vitellogenèse est induite dès la deuxième semaine. La testostérone puis l'œstradiol augmente dans le plasma ainsi que la vitellogénine. Ce résultat suggère un rôle des androgènes dans l'induction hépatique de la vitellogenèse. Les études in vitro sur les hépatocytes d'anguille maintenus en culture primaire ont mis en évidence la compétence des œstrogènes et des androgènes à stimuler la synthèse de vitellogénine. Un effet amplificateur de l'hormone de croissance bovine (bGH) sur la synthèse de vitellogénine par des doses faibles de E2 a été mis en évidence in vivo et in vitro, suggérant une action directe de la GH sur le foie. Les récepteurs hépatiques de l'œstradiol (RE2) ont été caractérisés ; ils s'apparentent à la famille des récepteurs nucléaires des stéroïdes. Ils sont présents en quantité trés faible dans le foie de l'anguille jaune ou argentée. Les premiers résultats obtenus suggèrent que l'action de la GH pourrait être associée à une synthèse de RE2 dans le foie. Des différences dans l'induction de la vitellogenèse par la gonadotropine de carpe sont mises en évidence entre les anguilles jaunes et argentées. II semble que différentes lipoprotéines participent à l'élaboration du vitellus. L'induction et le contrôle de la vitellogenèse sont plurihormonaux.

Mots-clés : hormone gonadotrope, ovocytes, stéroïdes sexuels, hormone de croissance, lipoprotéines, récepteurs hépatiques de l'œstradiol. 


\title{
OOGENESIS IN THE EEL (ANGUILLA ANGUILLA L.) : OOCYTE ULTRASTRUCTURE AT DIFFERENT STAGES OF DEVELOPMENT AND ROLE PLAYED BY LIPOPROTEINS DURING VITELLOGENESIS.
}

\begin{abstract}
Eels belong to two stages of development : yellow during which the fish feed and grow and silver when eels fasted and started their reproductive migration. This cycle is especially interesting to study the hormonal induction of oogenesis and especially vitellogenesis, important step in which oocytes incorporate vitellogenin, the precursor molecule for yolk. First, this paper describes different available criteria for vitellogenesis in the eel (lipoprotein characterization, oocyte ultrastructure, sex steroïds and vitellogenin plasma levels, hepatic receptors for estradiol (E2R)) and second, the effects of gonadotropic or steroïd treatments on the hormonal regulation of vitellogenesis by means of these criteria. Two classes of lipoproteins, VLDL (very low density lipoprotein) and HDL (high density lipoprotein), were found in both yellow and silver eel plasma but LDL (low density lipoprotein) was lacking. Differences in apolipoprotein composition of HDL were found between yellow and silver eel. In vivo estradiol priming induced an important increase in plasma VLDL and VHDL (very high density lipoprotein or vitellogenin) levels and suggested a role of these molecules during vitellogenesis. The ultrastructure of the eel oocyte showed the presence of endocytosic structure only in silver eel oocytes. This result suggests yellow eels as pre-vitellogenic and silver eels as vitellogenic. After gonadotropic injections, plasma estradiol (E2) levels alone rose. Vitellogenin slowly appeared after a long treatment. Vitellogenesis was much more quicker in silver eels than in yellow eels. Androgens and estrogens were both secreted in the plasma thus suggesting a role for androgens in the induction of hepatic vitellogenesis. In vitro assays on eel hepatocytes in primary culture shown a stimulatory effect on vitellogenin synthesis with E2 and high dosages of androgens. In vivo studies had shown a role of growth hormone (GH) during vitellogenesis. The action of $\mathrm{GH}$ was confirmed in vitro suggesting that $\mathrm{GH}$ acts directly on the liver to increase vitellogenin synthesis. RE2 were identified; they belong to the nuclear steroid receptor family. However they are present in the eel liver at a low concentration. GH seems to play a role on the synthesis of RE2. Differences exist between yellow and silver eels in the responses to gonadotropins. VLDL and vitellogenin are implicated in the oocytes for yolk formation. Hormonal induction and control of vitellogenesis are plurihormonal.
\end{abstract}

Key-words : gonadotropin oocytes, sex steroïds, growth hormone, lipoproteins, estradiol hepatic receptors.

\section{INTRODUCTION}

Les anguilles en eaux douces peuvent être capturées à deux stades distincts de développement. Au stade «jaune», elles assurent leur croissance. Les ovaires sont alors immatures et représentent environ de 0,3 à $0,8 \%$ du poids corporel (rapport gonadosomatique ou RGS). Puis une transformation importante, l'argenture, conduit au stade "argenté". L'anguille arrête de s'alimenter ; c'est un jeûne physiologique. L'ovaire atteint des RGS de 1,2 à 2,0\% environ. Les poissons s'apprêtent à entreprendre la migration de reproduction vers l'aire de ponte dans la mer des Sargasses (FONTAINE M., 1975 ; SINHA et JONES, 1975 ). A ce moment, la vitellogenèse commence ; celle-ci correspond à l'ensemble des processus physiologiques qui permettent à l'œuf d'accumuler les réserves vitellines. Quand les anguilles sont capturées au départ de la migration de reproduction, la vitellogenèse reste bloquée au développement auquel le poisson est parvenu. Un développement artificiel des gonades s'obtient par des injections d'extraits hypophysaires de poissons; ce fait permet l'obsenvation de la vitellogenèse et de la ponte chez l'anguille (FONTAINE M. et al., 1964 ; FONTAINE Y.A. et al., 1976). Les anguilles argentées constituent un outil biologique intéressant à bien des titres : l'anguille doit faire face à d'importantes modifications du métabolisme pour accomplir la vitellogenèse et assumer ses besoins énergétiques (FONTAINE M., 1975). Les poissons utilisent les lipides 
plutôt que les carbohydrates comme source d'énergie. Les lipoprotéines plasmatiques sont des molécules indispensables pour le transport plasmatique des lipides. Les acides gras, les phospholipides et le cholestérol sont ainsi amenés vers les tissus consommateurs d'énergie pour la constitution des membranes cellulaires et pour la synthèse de la vitellogénine, lipoprotéine hépatique précurseur du vitellus. Les hormones de la reproduction pourraient jouer un rôle important dans les modifications métaboliques de l'anguille. L'objectif de cet article est de décrire les données que nous avons obtenues chez les anguilles jaunes, comme valeurs de base, puis chez l'anguille argentée au moment de la capture. Nous étudierons les paramètres de la reproduction dans des conditions expérimentales variées.

\section{DONNÉES DE BASE SUR LES STRUCTURES PHYSIOLOGIQUES IMPLIQUÉES DANS LA VITELLOGENĖSE}

\section{Les lipoprotéines plasmatiques et la vitellogénine}

Les lipoprotéines sont des complexes macromoléculaires hydrophiles qui assurent le transport des lipides hydrophobes dans le plasma. Sur le plan chimique, une lipoprotéine est constituée d'une partie lipidique comprenant des molécules de phospholipides, de triglycérides, de cholestérol estérifié, de cholestérol libre, d'acides gras non estérifiés et d'une partie protéique appelée apolipoprotéine, composée de polypeptides monocaténaires. Une lipoprotéine spécifique des espèces ovipares, la vitellogénine est présente dans le plasma au cours de la vitellogenèse. Alors que chez les Mammifères, les lipoprotéines autres que la vitellogénine ont fait l'objet de nombreuses recherches, les données sont rares chez les poissons et ne concernent qu'un petit nombre d'espèces (cf. revue BABIN et VERNIER, 1989).

\subsection{Caractérisation des lipoprotéines chez l'anguille jaune et argentée}

Les différentes classes de lipoprotéines plasmatiques ont été caractérisées chez l'anguille argentée et chez l'anguille jaune par ultracentrifugation du sérum sur gradient discontinu de densité selon la méthode utilisée chez la truite (CHAPMAN et al., 1978).

Les résultats montrent que, aux deux stades, les lipoprotéines sont présentes sous forme de HDL (high density lipoprotein) et sous forme de VLDL (very low density lipoprotein). Les LDL, lipoprotéines de faible densité, n'existeraient pas ou à l'état de trace (Figure 1). Les HDL représentent la classe prédominante chez l'anguille argentée comme chez la plupart des Téléostéens (BABIN, 1987). Les VLDL sont plus importantes quantitativement chez l'anguille jaune que chez l'anguille argentée. L'analyse de la composition en protéines et lipides des HDL et VLDL indique que, chez l'anguille jaune, elles sont plus riches en protéines (59\% de protéines chez la jaune contre $49 \%$ chez l'argentée pour les HDL, et $23 \%$ contre $12 \%$ pour les VLDL). La composition en lipides des HDL et des VLDL est décrite en ce qui concerne l'anguille argentée dans le tableau IV.

La vitellogénine $(\mathrm{Vg})$ est une lipoprotéine de très haute densité (VHDL) synthétisée dans le foie ; elle apparaît dans le plasma des Vertébrés non mammaliens sous l'action des œestrogènes. Elle est plus riche en protéines et transporte des phospholipides et du cholestérol (cf. Figure 7).

\subsection{Composition en apolipoprotéines}

Les apolipoprotéines des HDL et des VLDL ont été analysées en électrophorèse sur gel de polyacrylamide. Cette étude révèle chez l'anguille argentée la présence de deux bandes de 200 et 190 kilodalton (kD) au niveau des VLDL, représentant l'apolipoprotéine de type $B$ et une bande de $24 \mathrm{kDa}$ au niveau des HDL, représentant l'apolipoprotéine de type Al (Figure 1B). Chez l'anguille jaune, ces apolipoprotéines sont également présentes mais en quantités plus importantes. A ce stade, d'autres protéines apparaissent aussi (de 44 et $47 \mathrm{kDa}$ ) mais celles-ci n'ont pu être identifiées chez l'anguille argentée (Figure 1C 1D). 
Bull. Fr. Pêche Piscic. (1994) 335 : 213-233 - 216 -

ANGUILLE ARGENTEE

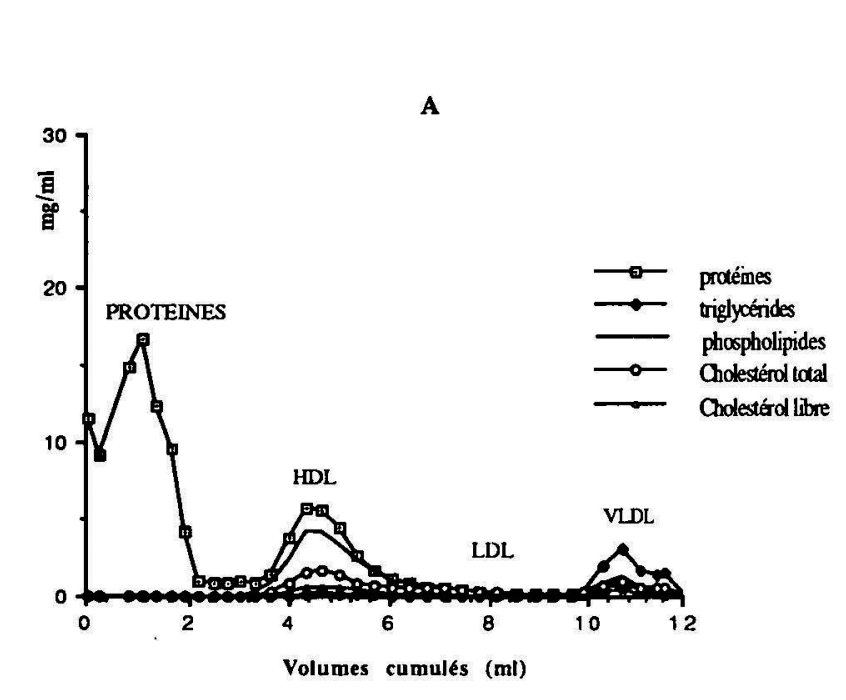

ANGUILLE JAUNE

HDL

VLDL

D

C

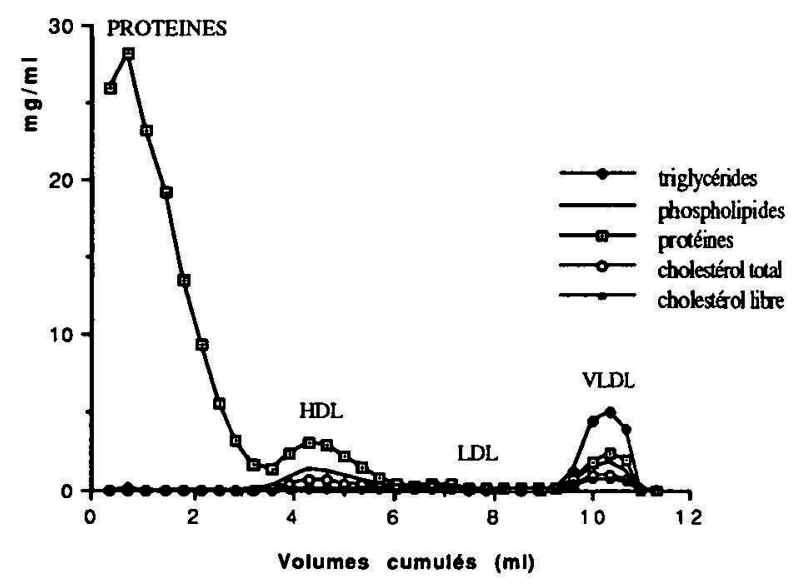

HDL

VLDL

Figure 1 (A, B, C, D) 
Figure 1 : Profil de séparation des différentes classes de lipoprotéines par ultracentrifugation en gradient discontinu de densité chez l'anguille argentée (A) et chez l'anguile jaune (B).

Analyse des apolipoprotéines des HDL (high density lipoprotein) et des VLDL (very low density lipoprotein) par électrophorèse en gel de polyacrylamide-SDS chez l'anguille argentée (C) et chez l'anguille jaune (D). Le plasma des anguilles $(1 \mathrm{ml})$ est ajusté à la densité de 1,31 avec du $\mathrm{NaBr}$ et analysé par ultracentrifugation en gradient discontinu de densité (24 heures à $180000 \mathrm{~g}-10^{\circ} \mathrm{C}$ ). Les HDL (high density lipoprotein) sédimentent pour la densité de 1,204 et les VLDL (very low density lipoprotein) flottent à la surface pour une densité de 1,009. Les protéines sont dosées selon BRADFOFD (1976) et les lipides à l'aide de kits Boehringer-Mannhein (Meylan, France) dans les différentes fractions.

Les électrophorèses sont réalisées en gradient linéaire de 3 à $20 \%$ polyacrylamide, $0,1 \%$ SDS et $1 \%$ glycerol. Les gels sont colorés par la technique au nitrate d'argent.

Figure 1 : Distribution of the different classes of lipoproteins by discontinuous density gradient ultracentrifugation of plasma from silver eel $(A)$ and yellow eel (B).

Analysis on SDS-polyacrylamide gel electrophesis of the apolipoproteins from HDL (high density lipoprotein) and VLDL (very low density lipoprotein) in silver eel (C) and in yellow eel (D).

Eel plasma $(1 \mathrm{ml})$ was adjusted to a density of 1,31 with $\mathrm{Na} \mathrm{Br}$ and analysed by discontinuous density gradient ultracentrifugation $\left(24\right.$ hours at $180000 \mathrm{~g}-10{ }^{\circ} \mathrm{C}$ ). HDL (high density lipoprotein) were found for a density of 1.204 and VLDL (very low density lipoprotein) for a density of 1.009. Proteins (BRADFOFD 1976) and lipids (kits Boehringer-Mannhein Meylan, France) were assayed in each fraction.

Electrophoresis were run in linear gradient of 3 à $20 \%$ polyacrylamide, 0,1 \% SDS and $1 \%$ glycerol. Gels were stained with silver nitrate. 


\subsection{Conclusions}

La comparaison des résultats entre l'anguille jaune et l'anguille argentée montre des différences quantitatives à la fois de la composition protéique et lipidique des lipoprotéines. Ces différences, entre l'anguille jaune qui s'alimente et l'anguille argentée, pourraient être la conséquence de l'état de jeûne physiologique des anguilles argentées, d'une part, mais aussi de l'induction de la vitellogenèse, d'autre part.

Des différences qualitatives existent aussi au sein des HDL : un type d'apolipoprotéine est absent des HDL chez l'anguille argentée. Ces données ouvrent des perspectives pour la mise au point de tests d'argenture : par exemple en purifiant ces apolipoprotéines à partir des HDL des anguilles jaunes pour l'élaboration de dosages ELISA (Enzyme Linked Immuno Sorbant Assay) spécifiques à l'aide d'anticorps préparés pour ces apolipoprotéines.

\section{L'ovocyte en relation avec le stade de la vitellogenèse}

\subsection{Description de l'ovocyte chez l'anguille jaune}

L'ovocyte s'identifie en histologie photonique par un noyau à nombreux nucléoles situé à la périphérie nucléaire et par l'absence d'inclusion cytoplasmique. C'est un ovocyte typiquement pré-vitellogénique, préparant l'activité synthétique et endocytotique de la vitellogenèse (LOPEZ et FONTAINE, 1990).

Ces caractéristiques pré-vitellogéniques sont mises en évidence en microscopie électronique. La phase d'amplification nucléaire se caractérise par la présence de nombreux nucléoles internes (non illustrée). Le cytoplasme présente des mitochondries et de nombreux ribosomes issus de l'activité nucléaire. La membrane plasmique ovocytaire ou oolemme, est accolée à la membrane plasmique des cellules de la granulosa. Toutefois, on peut observer de place en place l'initiation de bouquets de microvillosités ovocytaires. Les enveloppes ovocytaires sont très minces. Granulosa et cellules thécales sont présentes et séparées par une lame basale (Figure 2).

\subsection{Description de l'ovocyte chez l'anguille argentée}

L'ovocyte est caractérisé en microscopie photonique par la présence de globules dans le cytoplasme. L'approche en microscopie électronique (Figure $3 \mathrm{~A}$ et $3 \mathrm{~B}$ ) révèle qu'en réalité le follicule ovocytaire est déjà en vitellogenèse. En effet, la zona radiata externa est en cours de dépot entre les microvillosités ovocytaires s'érigeant dans une matrice extracellulaire sécrétée entre l'oolemme et la granulosa. A la base de ces microvillosités, on visualise des vésicules à clathrine d'endocytose et des vésicules vitellines provenant de la fusion des vésicules d'endocytose. Leur structure granulaire et leur aspect crénelé sont caractéristiques et correspondent à la phase de remaniement de la vitellogénine à l'intérieur de l'ovocyte. Le cytoplasme ovocytaire contient des mitochondries disséminées entre de nombreux globules lipidiques et présente des vésicules de réticulum endoplasmique. Cette activité synthétique reste toutefois discrète et ne peut s'observer qu'avec une approche ultrastructurale. Les cellules de la granulosa et de la thèque sont toujours très minces.

\subsection{L'ovocyte chez l'anguille argentée après stimulation gonadotrope}

Le follicule ovocytaire de l'anguille argentée traitée par de la gonadotropine de carpe est typiquement vitellogénique dès l'observation en microscopie photonique. La zona radiata est visible et de petits globules vitellins sont identifiables en périphérie ovocytaire entre les nombreux globules lipidiques. La microscopie électronique révèle une structure fibrillaire en arceaux correspondant à la mise en place d'une zona radiata externa homogène. Dans le cytoplasme périphérique on peut voir, entre des mitochondries présentes en quantité très importante, de nombreux dyctiosomes de l'appareil de Golgi disséminés entre les nombreux globules lipidiques. Les cellules de la granulosa se sont fortement développées. Elles ne semblent pas présenter de microvillosités folliculaires dirigées vers l'ovocyte. En effet, sur coupes tangentielles de la zona radiata, on ne distingue qu'une microvillosité d'origine ovocytaire par trou. Les cellules thécales, toujours minces, sont plus développées que dans les stades prédédents (Figure 4). 


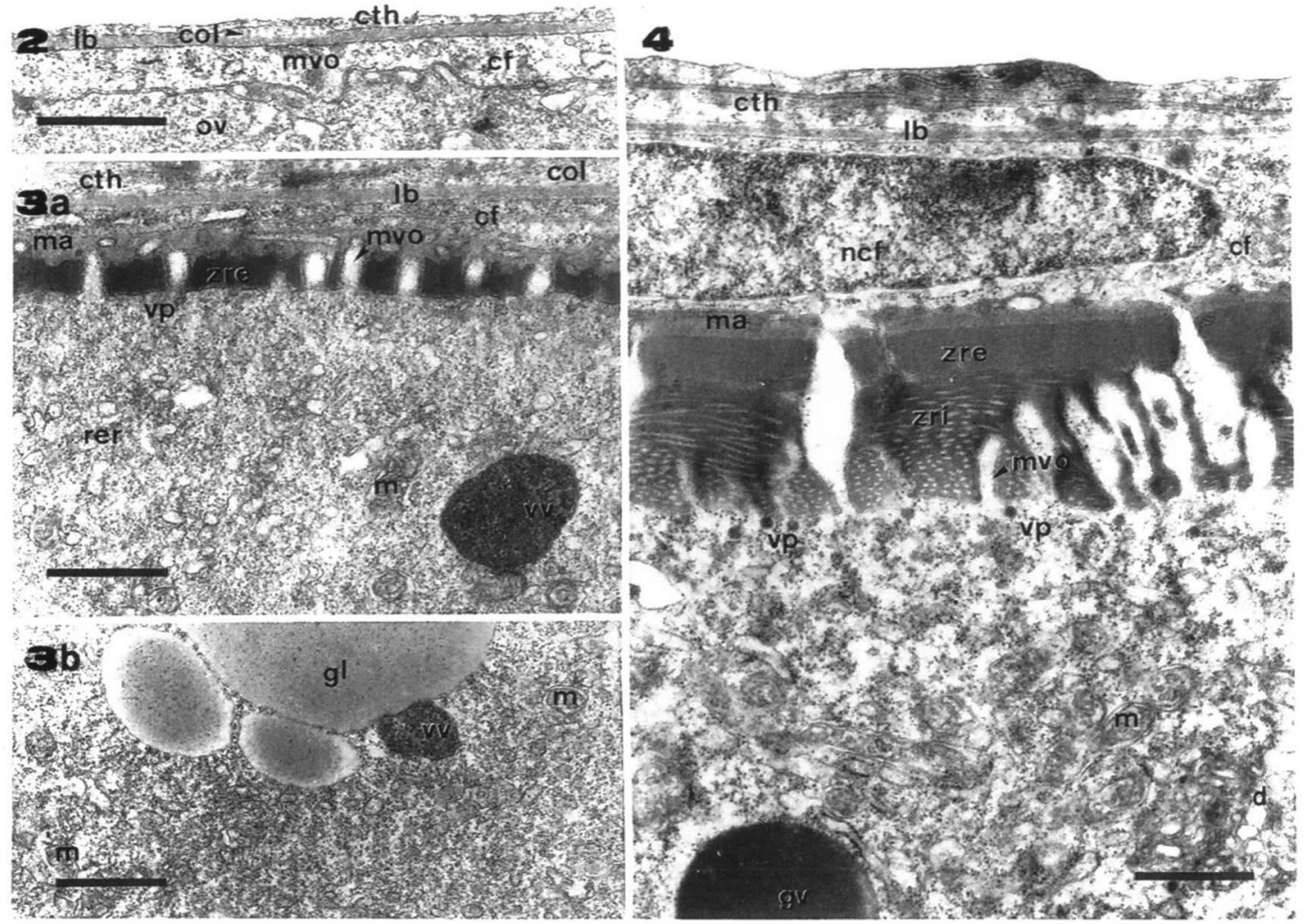

Figure 2 : Ultrastructure de l'ovocyte chez l'anguille jaune.

Figure 2 : Ultrastructure of the yellow eel oocyte.

Figure 3A, 3B : Ultrastructure de l'ovocyte chez l'anguille argentée.

Figure 3A, 3B : Ultrastructure of the silver eel oocyte.

Figure 4 : Ultrastructure de l'ovocyte chez l'anguille argentée après un traitement à la gonadotropine de carpe.

Ib : lame basale ; col : collagène ; $c$ th : cellules thécales ; mvo : microvillosités ovocytaires ; cf : cellules de la granulosa ; ov : ovocyte ; ma : matrice extraovocytaire ; zre : zona radiata externa ; vp : vésicule de pinocytose ; rer : reticulum endoplasmique rugueux ; $m$ : mitochondrie ; $v$ v : granule vitellin ; gl : globule lipidique ; ncf : noyau cellule folliculaire ; zri : zona radiata interna ; d : dictyosome ; gv : globule vitellin.

Figure 4 : Ultrastructure of silver eel oocyte after carp gonadotropin treatment.

Ib : basal lamina ; col : collagen ; $c$ th : thecal cells ; mvo : follicular microvillosities ; cf : granulosa cells ; ov : oocyte ; ma : extra-oocyte matrice ; zre : zona radiata externa ; vp : pinocytosis vesicle; rer : rough endoplasmic reticulum; $m$ : mitochondria ; v v : yolk granule; gl : lipid globule; ncf : granulosa cells nucleus ; zri : zona radiata interna; d : dictyosome ; gv : yolk globules. 


\subsection{Conclusions}

L'ultrastructure de l'ovaire de l'anguille jaune met en évidence un état d'immaturité dans lequel aucune des structures ovocytaires permettant l'endocytose de la vitellogénine n'est présente. Par contre, chez l'anguille argentée, les structures propres à l'endocytose ont été élaborées. L'action de la gonadotropine permet d'observer une intense amplification de leur développement par rapport à ceux des anguilles témoins. II faut également souligner que, chez l'anguille, il n'y a qu'une unique microvillosité d'origine ovocytaire contrairement à d'autres espèces où une deuxième, d'origine folliculaire, est présente. $\mathrm{Ce}$ fait peut résulter d'un développement encore faible de l'ovaire : aucune image ultrastructurale n'étant disponible pour des RGS supérieurs à 6 .

\section{Le récepteur de l'œstradiol (RE2) dans le foie d'anguille}

La synthèse de la vitellogénine dans le foie est sous le contrôle d'un récepteur nucléaire spécifique de l'œstradiol (RE2). Une technologie spécifique pour l'anguille a été mise au point pour déterminer les paramètres physico-chimiques de cette protéine : capacité maximale de liaison de E2 (Cmax), constante de dissociation (KD) dans les compartiments cytosolique et nucléaire des hépatocytes (cf. Tableau II) (MESSAOURIDEBOUN et al., 1991a). La liaison est spécifique de l'œstradiol.

Les KD des RE2 déterminés chez l'anguille sont en accord avec ceux observés chez les autres poissons Téléostéens. Les capacités maximales de liaison de E2 sont très faibles chez l'anguille et s'apparentent à celles trouvées pour des animaux immatures.

\section{INDUCTION EXPÉRIMENTALE DE LA VITELLOGENĖSE PAR DES EXTRAITS HYPOPHYSAIRES OU PAR LA GONADOTROPINE DE CARPE}

Le développement de la vitellogenèse chez l'anguille peut être obtenu expérimentalement par des injections d'extraits hypophysaires $(\mathrm{EHC})$ ou de gonadotropine de carpe (cGTH). Ce travail a permis d'obsenver les modifications des concentrations des hormones sexuelles dans le plasma (LELOUP-HATEY et al., 1988) et leur synchronisme avec l'apparition de la vitellogénine plasmatique (PEYON et al., en préparation).

\section{Action sur les stéroïdes et la vitellogénine plasmatiques}

\subsection{Anguille jaune}

Une augmentation significative de la concentration plasmatique de l'œstradiol (E2) est observée après un traitement avec EHc pendant 3 semaines. II n'y a pas de modification de la concentration plasmatique de testostérone (T) (Tableau I).

La vitellogénine plasmatique reste indétectable après le traitement de 3 semaines avec I' EHc ou avec la cGTH. Mais, après 7 semaines d'injection, la Vg commence à apparaître dans le plasma à la fois avec EHc et cGTH. Après 3 semaines, il n'y a pas d'augmentation significative du RGS alors qu'elle apparaît après la 7ème semaine (Tableau I).

\subsection{Anguille argentée}

L'activité stéroïdogénique de l'ovaire est stimulée. La concentration plasmatique de T augmente jusqu'au 7ème jour de 1 à $10 \mathrm{ng} / \mathrm{ml}$ puis diminue progressivement à $6 \mathrm{ng} / \mathrm{ml}$ après 8 semaines de traitement. Les niveaux de $5 a$-androstane-3ß,17ßdiol suivent ceux de la testostérone (LELOUP-HATEY et al., 1988) L'œstradiol plasmatique augmente faiblement de 1 à $3 \mathrm{ng} / \mathrm{ml}$ après 2 semaines (LELOUP-HATEY et al.,1988).

Les niveaux plasmatiques de $\mathrm{Vg}$ augmentent progressivement au cours d'une première phase de 3 à 4 semaines de 0,07 à $2 \mathrm{mg} / \mathrm{ml}$. Une deuxième phase succède pendant laquelle la teneur en $\mathrm{Vg}$ plasmatique baisse à $1 \mathrm{ng} / \mathrm{ml}$ à la 7ème semaine : c'est le début de l'incorporation massive de la vitellogénine dans l'ovocyte (Figure 5). 
Tableau I : Effet d'extraits hypophysaires de carpe (EHc) ou de gonadopropine de carpe (cGTH) sur les taux circulants de stéroïdes et de vitellogénine chez l'anguille jaune.

Les anguilles $(269,4 \pm 6,4 \mathrm{~g}-\mathrm{n}=30$ ) reçoivent pendant 3 ou 7 semaines, $0,5 \mathrm{ml}$ d'extrait hypophysaire de carpe (EHc $=250$ ou $750^{\star} \mu \mathrm{g} / \mathrm{kg} / \mathrm{injection}$ ) ou d'une solution de gonadotropine de carpe $(c \mathrm{GTH}=18,5 \mu \mathrm{g} / \mathrm{kg} / \mathrm{ml}$ ) à raison d'une injection 3 fois par semaine. Les anguilles témoins reçoivent le solvant. L'œstradiol et la testostérone sont dosés respectivement par RIA (QUERAT et al., 1985) et la vitellogénine par ELISA (BURZAWA-GERARD et al., 1991) sur les plasmas de chacune des anguilles. Les valeurs représentent les moyennes \pm l'erreur standard de la moyenne - nd détermination non réalisée.

Table I : Effect of carp pituitary extracts (EHc) or of carp gonadotropin (CGTH) on plasma steroïds and vitellogenin levels in the yellow eel.

Eels $(269.4 \pm 6.4 \mathrm{~g}-\mathrm{n}=30)$ received $5 \mathrm{ml}$ of pituitary extract $(E H c=250$ or $750^{*} \mu \mathrm{g} / \mathrm{kg} / \mathrm{ml}$ ) or a solution of carp gonadotropin (cGTH $=18.5 \mu \mathrm{gkg} / \mathrm{ml}$ ) during 3 or 7 weeks 3 times per week. Controls were injected with the vehicle.

Estradiol and testosterone were respectively assayed using RIA (QUERAT et al., 1985) and vitellogenin by ELISA (BURZAWA-GERARD et al., 1991) in the plasma. Values represented the mean \pm s.e.m. - nd not determined.

\begin{tabular}{|c|c|c|c|c|c|}
\hline Traitements & $\begin{array}{c}\text { doses } \\
(\mu \mathrm{g} / \mathrm{kg} / \mathrm{inj})\end{array}$ & $\begin{array}{c}\text { Testostérone } \\
(\mathrm{ng} / \mathrm{ml})\end{array}$ & $\begin{array}{c}\text { CEstradiol } \\
(\mathrm{ng} / \mathrm{ml})\end{array}$ & $\begin{array}{l}\text { Vitellogénine } \\
(\mu \mathrm{g} / \mathrm{ml})\end{array}$ & RGS \\
\hline \multicolumn{6}{|c|}{ Durée du traitement : 3 semaines } \\
\hline Témoins & - & $0,57 \pm 0,08$ & $0,87 \pm 0,23$ & $\leq 0,02$ & $1,02 \pm 0,14$ \\
\hline cGTH & 18,5 & nd & nd & $\leq 0,02$ & $0,83 \pm 0,07$ \\
\hline $\mathrm{EHc}^{*}$ & 750 & $0,57 \pm 0,08$ & $4,48 \pm 0,44$ & $0,02 \pm 0,01$ & $0,77 \pm 0,06$ \\
\hline \multicolumn{6}{|c|}{ Durée du traitement : 7 semaines } \\
\hline Témoins & - & nd & nd & $\leq 0,02$ & $0,83 \pm 0,03$ \\
\hline cGTH & 18,5 & nd & nd & $38,3 \pm 34,1$ & $1,05 \pm 0,07$ \\
\hline EHc & 250 & nd & nd & $90,0 \pm 49,3$ & $1,34 \pm 0,09$ \\
\hline
\end{tabular}

\section{Action sur le récepteur hépatique de l'estradiol}

\subsection{Anguille jaune}

Après un traitement de 3 semaines, une importante augmentation de la capacité maximale de liaison dans la fraction cytosolique des extraits de foie est observée. Elle est 7,4 fois supérieure à celle des animaux témoins. Le KD n'est pas modifié par le traitement (Tableau II). Toutefois, la vitellogénine n'apparaît pas dans le plasma. Ce résultat suggère que la translocation vers le site nucléaire n'a pu se réaliser. Des expérimentations plus longues ont montré par contre qu'après 7 semaines de traitement, la vitellogénine commençait à apparaître dans le plasma (Tableau II). Cette observation suggère que l'hépatocyte de l'anguille jaune requiert des modifications pour que la synthèse de $\mathrm{Vg}$ soit possible. Les données concernant l'apparition de sites de liaison dans les fractions nucléaires ne sont pas actuellement disponibles chez l'anguille jaune. 


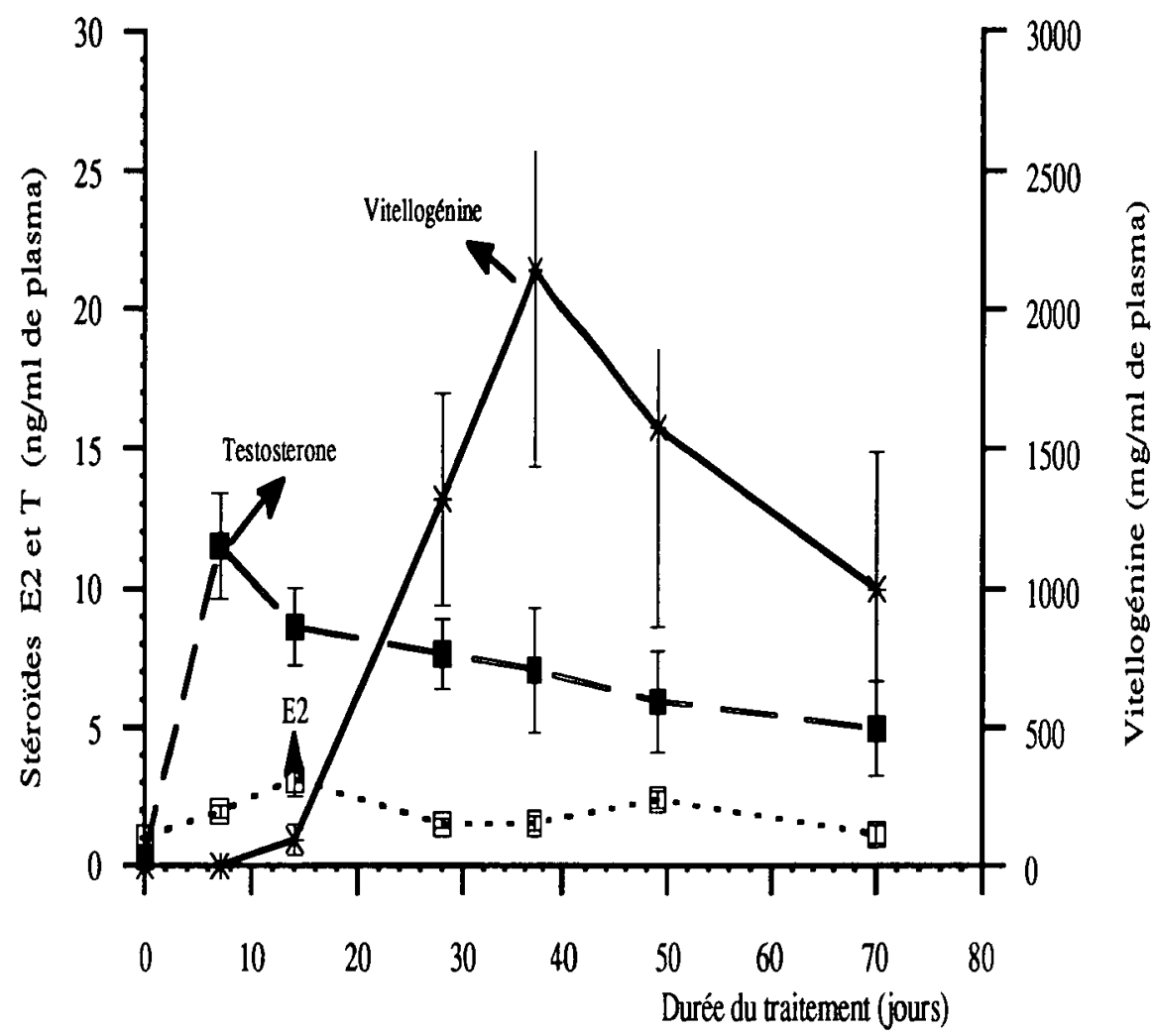

Figure 5 : Effet d'un traitement avec un extrait d'hypophyse de carpe sur les teneurs plasmatiques en CEstradiol (E2), Testostérone (T) et Vitellogénine (Vg) chez l'anguille argentée.

Sept anguilles argentées femelles $(660 \pm 48 \mathrm{~g})$ ont recu des injections (3 fois/semaine pendant 2 mois) de $1 \mathrm{mg}$ d'extrait d'hypophyse de carpe. Des prélèvements de sang sont pratiqués tous les 7 à 10 jours. Les concentrations plasmatiques de $\mathrm{Vg}$ sont estimées par ELISA (BURZAWA-GERARD et al., 1991) et celles de E2 et de T par RIA (QUERAT et al., 1985).

Figure 5 : Effect of treatment with a carp pituitary extract on Estradiol (E2), Testosterone ( $\mathrm{T}$ ) et Vitellogenin $(\mathrm{Vg})$ plasma levels in the silver eel.

Seven female silver eels $(660 \pm 48 \mathrm{~g})$ received injections $(3$ times/week during 2 months) of $1 \mathrm{mg}$ of carp pituitary extract. Blood samples were taken at 7 to 10 days intervals. Plasma Vg levels were assayed by ELISA (BURZAWA-GERARD et al., 1991) and plasma E2 and T levels by RIA (QUERAT et al., 1985).

\subsection{Anguille argentée}

A ce stade de développement, la Cmax est multipliée par 1,7. Ce sont les RE2 nucléaires qui sont concernés par cette augmentation La constante de dissociation (KD) n'est pas modifiée par le traitement. Dans ces conditions, la vitellogénine apparaît dans le plasma (cf. Tableau I). 
Tableau II : Effet de l'extrait hypophysaire de carpe (EHc) sur le récepteur hépatique de l'œstradiol chez l'anguille jaune et argentée.

Les anguilles $(269,4 \pm 6,4 \mathrm{~g}-\mathrm{n}=13$ anguilles jaunes ; $272,0 \pm 5,5 \mathrm{~g}-\mathrm{n}=10$ anguilles argentées) reçoivent l'extrait hypophysaire de carpe (EHc $=250 \mu \mathrm{g} / \mathrm{kg} / \mathrm{injection})$ 3 fois par semaine pendant 3 semaines. Les témoins reçoivent le solvant.

Les constantes de dissociation à l'équilibre (KD) ont été déterminées selon SCATCHARD (1949). Les capacités maximales de liaison (Cmax) sont calculées à partir de la liaison maximale pour 1,4 nM d'œstradiol. Les cœfficients de variation sont $\mathbf{2 5}$ et $\mathbf{3 6} \%$ respectivement dans chaque fraction hépatique (MESSAOURIDEBOUN, 1994).

Table II : Effect of carp pituitary extract $(\mathrm{EHc})$ on the estradiol hepatic receptor in yellow and silver eels.

Eels (yellow eels $269.4 \pm 6.4 \mathrm{~g}-\mathrm{n}=13$; silver eels $272.0 \pm 5.5 \mathrm{~g}-\mathrm{n}=10$ ) received a pituitary extract $(\mathrm{EHC}=250 \mu \mathrm{g} / \mathrm{kg} / \mathrm{injection}) 3$ times per week during 3 weeks. Controls animals received the vehicle.

The dissociation constants (KD) were determined according to SCATCHARD (1949). The maximal binding capacities were calculated from the determination of the maximal binding for $1.4 \mathrm{nM}$ estradiol. Variation coefficients are $25 \%$ and $36 \%$ respectively in each liver fraction (MESSAOURI-DEBOUN, 1994).

\begin{tabular}{ccccccc}
\hline Stade & \multicolumn{2}{c}{ Anguilles jaunes } & \multicolumn{4}{c}{ Anguilles argentées } \\
\hline $\begin{array}{c}\text { Nature de la } \\
\text { fraction }\end{array}$ & \multicolumn{2}{l}{ Fraction cytosolique } & Fraction nucléaire & Fraction cytosolique \\
\hline $\begin{array}{c}\text { Constantes } \\
\text { déterminées }\end{array}$ & $\begin{array}{c}\mathrm{KD} \\
(\mathrm{nM})\end{array}$ & $\begin{array}{c}\text { Cmax } \\
(\mathrm{fMoles} / \mathrm{g})\end{array}$ & $\begin{array}{c}\mathrm{KD} \\
(\mathrm{nM})\end{array}$ & $\begin{array}{c}\text { Cmax } \\
(\mathrm{fMoles} / \mathrm{g})\end{array}$ & $\begin{array}{c}\mathrm{KD} \\
(\mathrm{nM})\end{array}$ & $\begin{array}{c}\text { Cmax } \\
(\mathrm{fMoles} / \mathrm{g})\end{array}$ \\
\hline Témoins & 0,441 & 1,8 & 0,29 & $5,6 \pm 2,1$ & $0,62 \pm$ & $14,4 \pm 3,8$ \\
\hline EHc & 0,82 & 87,7 & 0,291 & $6,2 \pm 6,1$ & 0,21 & $16,7 \pm 0,2$ \\
\hline
\end{tabular}

\section{Conclusions}

La vitellogenèse peut être observée chez l'anguille après des traitements exogènes avec des extraits hypophysaires de carpe ou de gonadotropine de carpe. Toutefois des différences importantes apparaissent selon le stade de l'anguille. L'anguille jaune constitue un témoin idéal du temps zéro vis-à-vis de la vitellogenèse. Chez l'anguille argentée, l'analyse des réponses stéroïdogéniques montre qu'une relation existe entre la sécrétion des androgènes et celle de l'œstradiol, pour que la vitellogénine apparaisse dans la plasma. La cinétique de réponse de la vitellogénine plasmatique suggère que le foie est apte à amplifier la synthèse de la protéine et la structure de l'ovaire prête pour l'incorporation; ces transformations sont acquises au cours de l'argenture.

\section{RÉGULATION HORMONALE DE LA SYNTHĖSE HÉPATIQUE DES LIPOPROTÉINES PAR LES STÉROÏDES ET L'HORMONE DE CROISSANCE}

La comparaison des effets de la stimulation gonadotrope chez l'anguille met en évidence que l'induction de la vitellogenèse met en œuvre des systèmes de régulation complexes. L'hypophyse, le foie et l'ovaire sont les trois acteurs. Dans une première étape, nous avons recherché les actions individuelles de différents stéroïdes sexuels et de l'hormone de croissance sur les critères de la vitellogenèse que nous avons définis. Les résultats exposés dans ce chapitre concernent seulement les anguilles argentées. 


\section{Effet de l'œstradiol}

\subsection{Sur le récepteur de l'œstradiol (RE2)}

La capacité maximale de liaison des RE2 a été estimée dans les fractions cytosoliques et nucléaires. Parallèlement, les concentrations plasmatiques en E2 et en vitellogénine sont estimées. Les résultats sont résumés dans le tableau III :

— avec E2 injecté à $10 \mu \mathrm{g} / \mathrm{kg} /$ injection, la concentration plasmatique de E2 est environ 10 fois la teneur physiologique obtenue expérimentalement par des traitements gonadotropes. Dans ces conditions, la Cmax totale du foie est faiblement modifiée. De plus, la vitellogénine n'est pas détectée dans le plasma (MESSAOURI-DEBOUN et al., 1991b).

- quand la dose de E2 est multipliée par 50, la Cmax augmente d'environ 5 fois dans le compartiment nucléaire et diminue d'environ 2 fois dans la fraction cytosolique par rapport à celle des témoins. La vitellogénine plasmatique est alors considérablement augmentée (Tableau III). Des expérimentations complémentaires ont montré que, après un traitement chronique à E2, la vitellogénine apparaît dans le plasma quand la concentration plasmatique en E2 devient supérieure à 100 nM (MESSAOURI-DEBOUN, 1994).

Tableau III : Effet de traitements chroniques à l'CEstradiol sur la capacité de liaison des récepteurs de l'œstradiol (RE2) dans le foie d'anguille argentée.

Les anguilles $(217,4 \pm 5,8 \mathrm{~g}-n=11$ et $326,3 \pm 23,5-n=15$ pour chaque dose testée) reçoivent l'hormone en injection 3 fois par semaine pour la faible dose et une fois par semaine pour la forte dose pendant 3 semaines. Les poissons sont sacrifiés 24 heures après la dernière injection.

Les estimations des capacités maximales de liaison et des concentrations plasmatiques d'œstradiol et de vitellogénine sont décrites dans les tableaux I et II.

Table III : Effect of Estradiol chronic treatments on the maximal binding capacity of Estradiol receptors (E2R) in the silver eel liver.

Eels (217.4 $\pm \mathbf{5 . 8 g}-n=11$ et $326.3 \pm 23.5-n=15$ for each assayed dose) received during 3 weeks the hormone 3 times per week for the low dose and once per week for the high dose of E2. The fish were killed 24 hours after the last injection.

The maximal binding capacity and plasma estradiol and vitellogenin determinations are described in Tables I and II.

\begin{tabular}{cccccc}
\hline $\begin{array}{c}\text { CEstradiol } \\
\text { injecté } \\
(\mu \mathrm{g} / \mathrm{kg})\end{array}$ & \multicolumn{2}{c}{ Capacité maximale de liaison des RE2 } & & $\begin{array}{c}\text { OEstradiol } \\
\text { plasmatique } \\
(\mathrm{ng} / \mathrm{ml})\end{array}$ & $\begin{array}{c}\text { Vitellogénine } \\
\text { plasmatique } \\
\mu \mathrm{g} / \mathrm{ml})\end{array}$ \\
\cline { 2 - 5 } & $\begin{array}{c}\text { Fraction } \\
\text { cytosolique }\end{array}$ & $\begin{array}{c}\text { Fraction } \\
\text { nucléaire }\end{array}$ & $\begin{array}{c}\text { Total des } \\
\text { Fractions }\end{array}$ & & \\
\hline 0 & 56,4 & 2,9 & 59,3 & $0,15 \pm 0,03$ & $0,12 \pm 0,02$ \\
\hline 10 & 41,0 & 4,4 & 45,4 & $26,4 \pm 3,6$ & $0,28 \pm 0,11$ \\
\hline 0 & 7,0 & 6,1 & 13,1 & $1,22 \pm 0,33$ & $0,27 \pm 0,03$ \\
\hline 500 & 3,2 & 28,1 & 31,3 & $89,9 \pm 12,4$ & $2550 \pm 550$ \\
\hline
\end{tabular}




\subsection{Sur la synthèse de vitellogénine}

- in vivo : la cinétique des teneurs plasmatiques en $\mathrm{Vg}$ a été suivie après une injection de E2 $(625 \mu \mathrm{g} / \mathrm{kg}$ - E2 plasmatique d'environ $40 \mathrm{ng} / \mathrm{ml}$ (figure 6$)$. Les niveaux plasmatiques de $\mathrm{Vg}$ augmentent de $\leq 0,02 \mu \mathrm{g} / \mathrm{ml}$ à $450 \mu \mathrm{g} / \mathrm{ml}$ environ 4 jours après l'injection. Les réponses vitellogéniques d'une anguille à l'autre sont très variables (de 50 à $2500 \mu \mathrm{g} / \mathrm{ml})$.

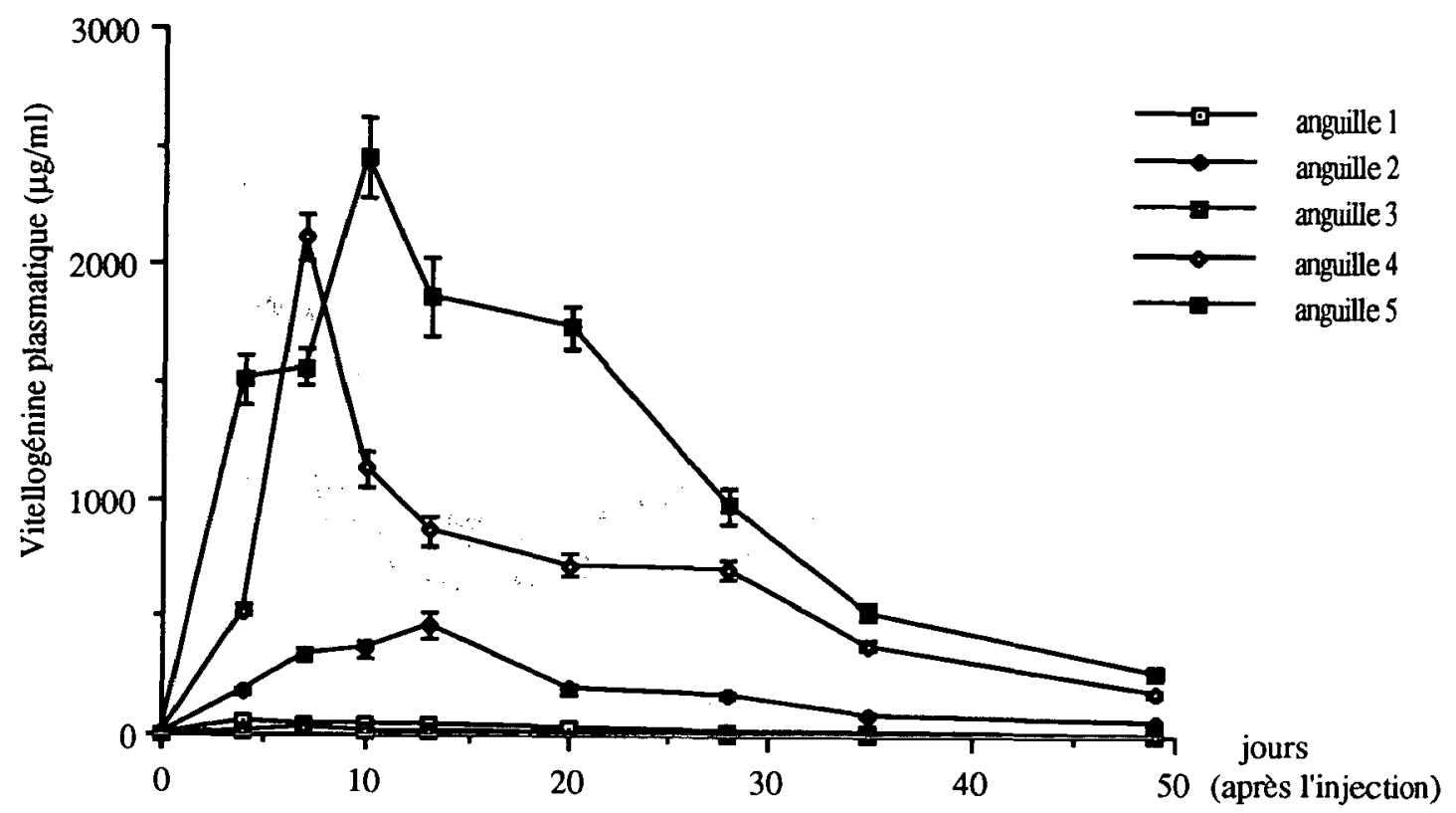

Figure 6 : Cinétique d'apparition de la vitellogénine plasmatique après une injection d'CEstradiol (E2) chez des anguilles argentées.

Cinq anguilles $(300 \pm 20 \mathrm{~g})$ reçoivent une injection d'cestradiol $(0,83 \mathrm{mg} / \mathrm{kg})$. Des prélèvements de sang sont réalisés de 4 à 10 jours d'intervalle pendant 50 jours. La vitellogénine est dosée par ELISA (BURZAWA-GERARD et al., 1991).

Figure 6 : Kinetic of plasma vitellogenin levels after one injection of Estradiol (E2) in silver eels.

Five eels $(300 \pm 20 \mathrm{~g})$ received one E2 intraperitoneal injection $(0,83 \mathrm{mg} / \mathrm{kg})$. Blood samples were taken at 4 to 10 days intervals during 50 days. Plasma $\mathbf{~ g g ~ l e v e l s ~ w e r e ~}$ assayed by ELISA (BURZAWA-GERARD et al., 1991).

- in vitro: en culture primaire d'hépatocytes d'anguille, la vitellogénine est sécrétée dans le milieu après 6 à 8 jours de culture, pour E2 $10^{-7} \mathrm{M}$. La réponse est significativement différente de celle des témoins et croît avec la dose de E2 (Figure 7A) (PEYON et al., 1993). 


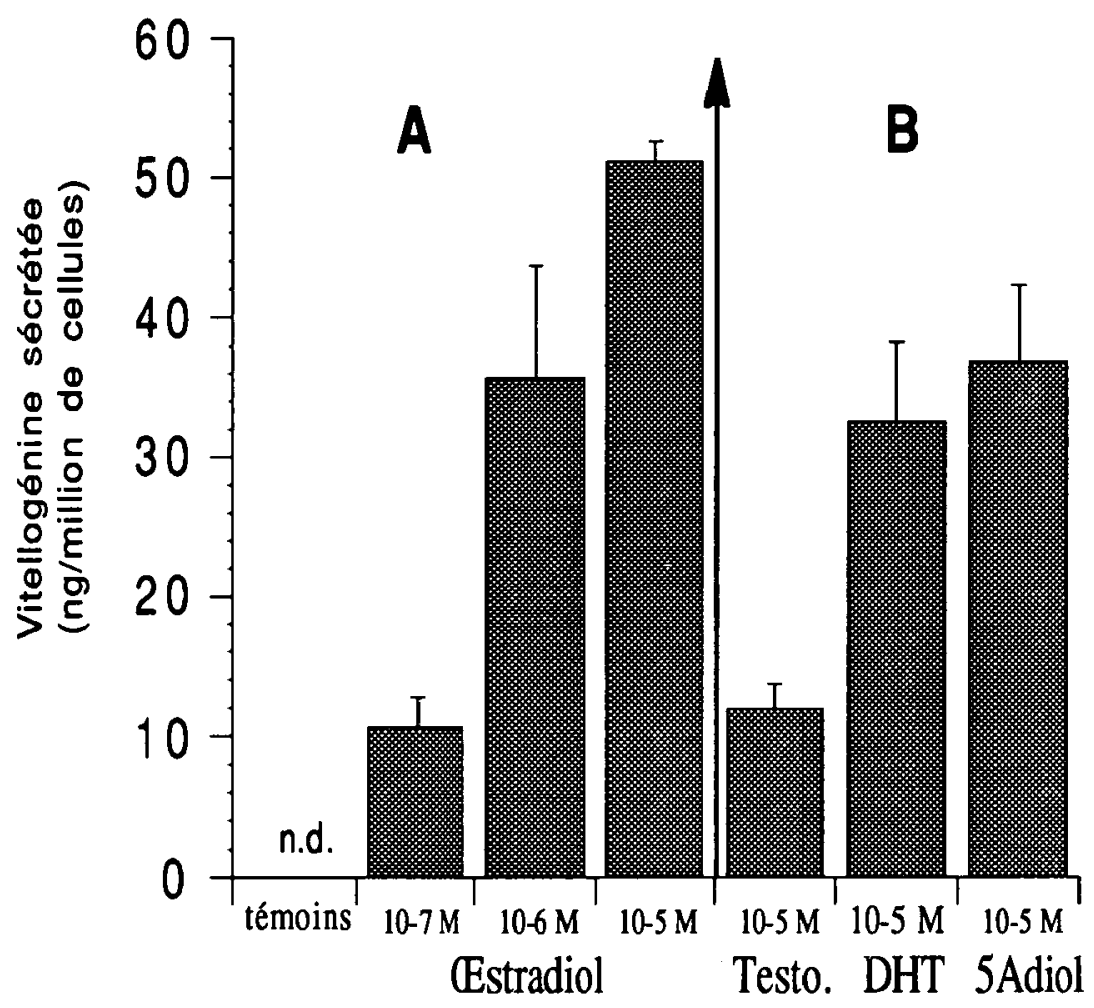

Figure 7 : Effet des stéroïdes sur la synthèse de vitellogénine in vitro par des hépatocytes d'anguille en culture primaire.

Les hépatocytes sont préparés à partir du foie d'une anguille pré-traitée 21 jours avant par une injection d'œstradiol $(625 \mu \mathrm{g} / \mathrm{kg})$ selon PEYON et al., 1993. Les données représentent la quantité de vitellogénine sécrétée dans le milieu de culture entre le 8ème et le 10ème jour de culture (moyenne \pm erreur standard de la moyenne ; $n=4$ ) en présence de différentes doses d'cstradiol (E2 10-7M à 10-5 M), de testostérone (T) $10^{-5} \mathrm{M}$, de $5 \alpha$-dihydrotestostérone (DHT) $10^{-5} \mathrm{M}$ ou $5 \alpha$ androstane-3 $\beta, 17 \beta$-diol (5Adiol) $10^{-5} \mathrm{M}$. La vitellogénine est dosée par ELISA (BURZAWA-GERARD et al., 1991).

Figure 7 : Effect of steroïds on the in vitro vitellogenin synthesis by eel hepatocytes in primary culture.

An eel, primed with E2 $(625 \mu \mathrm{g} / \mathrm{kg}) 21$ days before, was used to prepare the hepatocytes (PEYON et al., 1993). The data represent the amount of vitellogenin secreted in the medium between the 8th and the10th days of culture (mean \pm standard error of the mean ; $=4$ ) in presence of different dosages of estradiol ( $E 2$ $10^{-7} \mathrm{M}$ to $10^{-5} \mathrm{M}$ ), of testosterone (T) $10^{-5} \mathrm{M}$, of $5 \alpha$-dihydrotestosterone (DHT) $10^{-5} \mathrm{M}$ or of $5 \alpha$-androstane-3 $\beta, 17 \beta$-diol (5Adiol) $10^{-5} \mathrm{M}$. Vittellogenin was assayed by ELISA (BURZAWA-GERARD et al., 1991). 


\subsection{Sur la synthèse des lipoprotéines VLDL et HDL}

Un traitement de longue durée avec E2 s'accompagne, au niveau plasmatique, d'une importante augmentation des taux de triglycérides et de phospholipides ainsi que d'une diminution des teneurs en cholestérol estérifié. Ces modifications se traduisent par une augmentation importante de la concentration plasmatique des VLDL qui est multipliée par quatre par rapport à celle des anguilles témoins. La concentration des HDL n'est pas modifiée par le traitement. La Vg apparaît également en quantité importante dans le plasma. L'analyse du plasma par ultracentrifugation en gradient de densité montre la présence d'un pic de phospholipides et de cholestérol pour la densité de Vg (Figure 8).

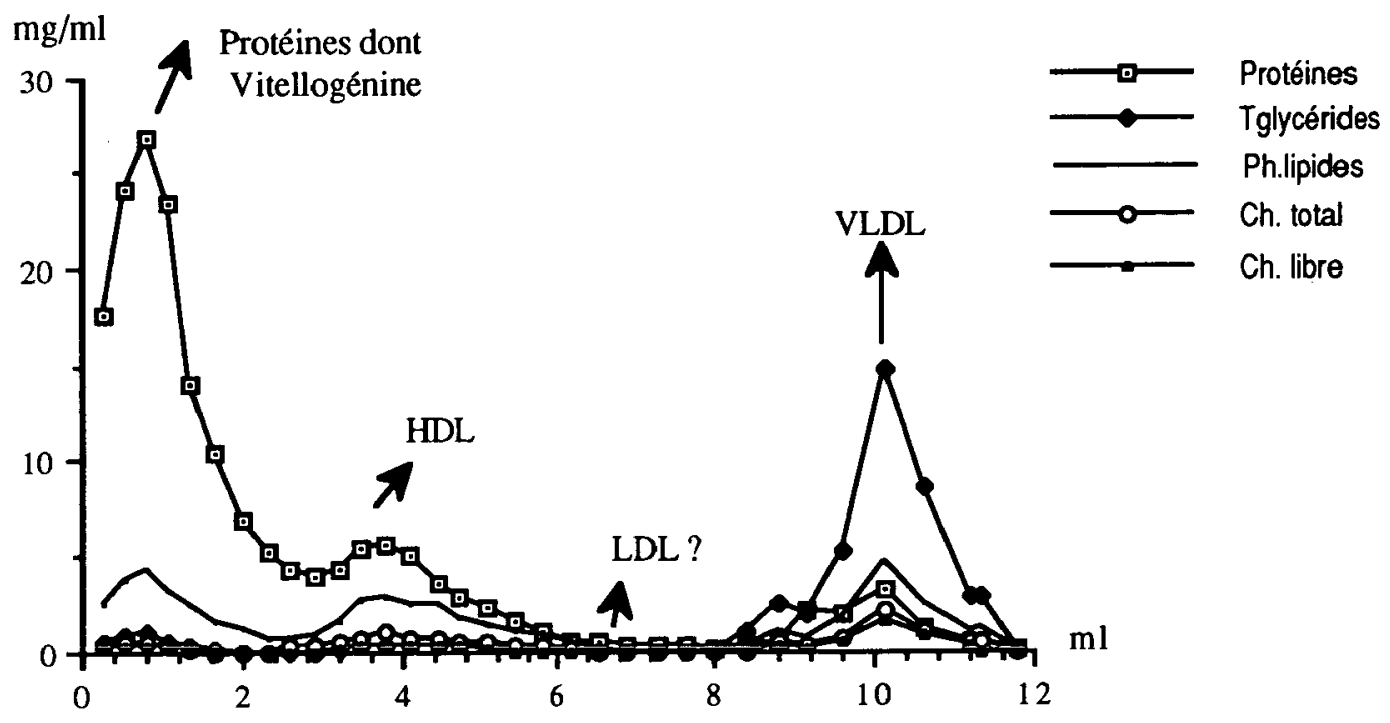

Figure 8 : Effet d'un traitement à l'Cstradiol (E2) sur le profil des lipoprotéines plasmatiques obtenu par ultracentrifugation en gradient discontinu de densité chez l'anguille argentée.

Les anguilles (450 $\pm 32 \mathrm{~g}-\mathrm{n}=5$ ) reçoivent l'E2 par injection intrapéritonéale ( $1 \mathrm{mg} / \mathrm{kg} / \mathrm{semaine}$ ) pendant 5 semaines. Le sang est recueilli par décapitation puis le plasma est immédiatement ultracentrifugé dans les conditions décrites pour la Figure 1.

Figure 8 : Effect of an Estradiol (E2) treatment on the profil of plasma lipoproteins obtained by discontinuous density gradient ultracentrifugation in silver eel.

The eels $(450 \pm 32 \mathrm{~g}-\mathrm{n}=5)$ received E2 injections $(1 \mathrm{mg} / \mathrm{kg} /$ week) during 5 weeks. The blood was collected after decapitation and immediately centrifugated as described in Figure 1.

La composition des deux types de lipoprotéines (HDL et VLDL) est également altérée par le traitement à l'œstradiol. Outre une augmentation de la proportion des triglycérides des VLDL et des protéines des HDL, on observe dans les deux classes de lipoprotéines une diminution de la proportion du cholestérol estérifié (Tableau IV). 
Tableau IV : Effet de l'CEstradiol (E2) sur la composition des lipoprotéines plasmatiques chez l'anguille argentée.

Les anguilles $(538,8 \pm 116,6 \mathrm{~g}-\mathrm{n}=10)$ sont traitées avec E2 (1 mg/semaine) en injection pendant 8 semaines. Les lipoprotéines sont séparées par ultracentrifugation comme décrit Figure 1 (HDL : high density lipoprotein - VLDL : very low density lipoprotein). Les protéines et les différents lipides sont estimés comme décrit Figure 1.

Table IV : Effect of Estradiol (E2) on the composition of plasmatic lipoproteins in the silver eel.

- Eels $(538.8 \pm 116.6 \mathrm{~g}-\mathrm{n}=10)$ received injections of E2 $(1 \mathrm{mg} /$ week) during 8 weeks. Lipoproteins were separeted by ultracentrifugation as described in Figure 1. Proteins and lipids are assayed as described in Figure 1.

\begin{tabular}{lccccc}
\hline Pourcentage & Protéines & Triglycérides & Phospholipides & $\begin{array}{c}\text { Cholestérol } \\
\text { estérifié libre }\end{array}$ & Cholestérol \\
\hline HDL (témoin) & 47,9 & 2,6 & 35,9 & 9,4 & 4,2 \\
\hline HDL (E2) & 56,0 & 4,0 & 30,0 & 6,0 & 4,0 \\
\hline VLDL (témoin) & 11,7 & 50,0 & 21,7 & 10,0 & 6,6 \\
\hline VLDL (E2) & 9,1 & 59,3 & 19,4 & 2,0 & 6,4 \\
\hline
\end{tabular}

\section{Action des androgènes}

\subsection{Sur la synthèse de vitellogénine in vivo}

Les androgènes étudiés : testostérone, dihydrotestostérone $(5 \alpha \mathrm{DHT})$ et $5 \mathrm{a}$ androstane $3 \beta-17 ß-d i o l$ (5a-A-diol) en une seule injection (environ $1 \mathrm{mg} / \mathrm{ml}$ ) $\mathrm{n}^{i}$ induisent pas l'apparition de $\mathrm{Vg}$ dans le plasma. E2, sur le même lot expérimental, induit dès le 4ème jour, une augmentation importante de $\mathrm{Vg}$ plasmatique.

\subsection{Sur la synthèse de vitellogénine in vitro}

Les androgènes à fortes doses $\left(10^{-5} \mathrm{M}\right)$ induisent une synthèse dè $\mathrm{Vg}$ après 6 à 8 jours de culture. Les androgènes réduits non-aromatisables ( $5 \alpha-\mathrm{DHT}$ et $5 \mathrm{a}-\mathrm{A}$-diol) induisent une réponse 2.à 3 fois plus élevée que celle de la testostérone. La quantité de $V \mathrm{~g}$ sécrétée dans le milieu de culture avec la testostérone $\left(10^{-5} \mathrm{M}\right)$ est voisine de celle obtenue avec $10^{-7} \mathrm{M}$ de $\mathrm{E} 2$ (environ $10 \mathrm{ng} / 10^{6}$ de cellules). La réponse vitellogénique est plus importante avec $10^{-5} \mathrm{M} 5 \alpha$-A-diol : les quantités de $\mathrm{Vg}$ sécrétées sont du même ordre de grandeur que celles obtenues pour $10^{-6} \mathrm{M} \mathrm{E2}$ (environ $35 \mathrm{ng} / 10^{6}$ de cellules) (Figure $7 \mathrm{~B}$ ).

Des androgènes non aromatisables induisent la synthèse de vitellogénine dans les cultures d'hépatocyte d'anguille. L'action de la testostérone ne serait donc pas associée à l'existence d'une activité aromatase hépatique permettant sa transformation en E2. La recherche de corps oestrogéniques issus de l'aromatisation de la $T$ (identification de stéroïdes, extraction phénolique, séparation sur colonne de célite, CCM, HPLC) ainsi que le dosage direct de l'aromatase dans les milieux de culture se sont révélés négatifs (PEYON et al., en préparation). 


\section{Rôle de l'hormone de croissance (GH)}

\subsection{Sur la synthèse de vitellogénine}

- in vivo : diverses préparations d'hormones de croissance ( $\mathrm{GH}$ bovine, de saumon ou de carpe) ont été étudiées chez des anguilles normales ou hypophysectomisées en présence ou non d'œstradiol. Les taux circulants de vitellogénine ont été choisis comme indice de synthèse de la lipoprotéine. Les $\mathrm{GH}$ injectées seules ne modifient pas les taux circulants de $\mathrm{Vg}$. L'association de la GH et de $\mathrm{E} 2$, par contre, induit une potentialisation de l'effet vitellogénique de E2 seul. Les taux de Vg plasmatique sont multipliés par 5 avec la GH de saumon chez l'anguille hypophysectomisée et par 2 avec la $\mathrm{GH}$ bovine chez l'anguille normale (BURZAWA-GERARD et DELEVALLEE-FORTIER, 1992).

- in vitro : en culture primaire d'hépatocytes, l'effet potentialisateur de la GH bovine est retrouvé. L'addition de bGH dans le milieu de culture avec E2 conduit à augmenter considérablement la sécrétion de $\mathrm{Vg}$ comparée à celle produite avec la même dose de E2 (Tableau V). L'effet potentialisateur est dépendant de la dose de E2 et de GH (PEYON et al., données soumises à publication).

Tableau V : Effet de l'hormone de croissance bovine (bGH) sur la réponse vitellogénique induite par l'CEstradiol en culture primaire d'hépatocytes d'anguille argentée (PEYON et al., 1993).

L'anguille utilisée pour la culture a reçu 21 jours auparavant une injection de E2 $(625 \mu \mathrm{g} / \mathrm{kg})$. Les données représentent la quantité de vitellogénine sécrétée entre le $10^{e}$ et le $12^{e}$ jour de culture (moyenne \pm sem ; $\left.n=4\right)$. bGH $($ NIH lot S11) $=20 \mathrm{ng} / \mathrm{ml}$ de milieu.

* la sensibilité de l'ELISÁ est de $10 \mathrm{ng}$ de vitellogénine/10'cellules.

** valeurs significativement différentes entre les lots ( $p \leq 0,01$ test de Student) traités par E2 et E2 + bGH.

Table $V$ : Effect of bovine growth hormone (bGH) on the vitellogenic response induced by Estradiol in silver eel hepatocytes maintained in primary culture (PEYON et al., 1993).

The eel received an injection of E2 $(625 \mu \mathrm{g} / \mathrm{kg}) 21$ days before the culture. The amount of secreted vitellogenin were assayed between 10 to 12 days of culture by ELISA ( mean \pm sem ; $n=4$ ). bGH (NIH lot $S 11)=20 \mathrm{ng} / \mathrm{ml}$ of medium.

* the sensitivity of ELISA was $10 \mathrm{ng}$ of vitellogenin/106 cells.

** values significantly different between the batches $(p \leq 0,01$ Student's test) treated by E2 et E2 + bGH.

Vitellogénine sécrétée dans le milieu ( $\mathrm{ng} / 106 \cdot$ cellules)

\begin{tabular}{lcc}
\hline CEstradiol (M) & en absence de GH bovine & en présence de GH bovine \\
\hline 0 & $\leq 10^{\star}$ & $\leq 10^{\star}$ \\
\hline $10-7$ & $63,2 \pm 11,3$ & $2102 \pm 86^{\star \star}$ \\
\hline $10-5$ & $2878 \pm 169$ & $-3437 \pm 325^{\star \star}$ \\
\hline
\end{tabular}




\subsection{Sur le récepteur de l'œstradiol}

La capacité maximale de liaison du foie est modifiée par le traitement à la bGH. Une augmentation importante apparaît dans la fraction cytosolique (4 fois) (Figure 9 - 1ère expérience) ; les concentrations plasmatiques de stéroïdes sexuels ( $E 2 \quad 0,15 \mathrm{ng} / \mathrm{ml} ; T 1,0 \mathrm{ng} / \mathrm{ml}$ ) ou de $\mathrm{Vg}( \pm 0,02 \mathrm{mg} / \mathrm{ml})$ ne sont pas modifiées par rapport à celles des témoins. Par contre, l'association de bGH et de E2 entraîne une importante augmentation de la capacité maximale de liaison dans la fraction nucléaire (Figure 9 - 2ème expérience). Ce résultat suggère que la bGH induit une synthèse des RE2 hépatiques présents dans la fraction cytosolique sous leur forme inactive. Un apport de E2 est nécessaire pour les transférer dans la fraction nucléaire où ils exerceront leur action sur le génome.

lère Expérience

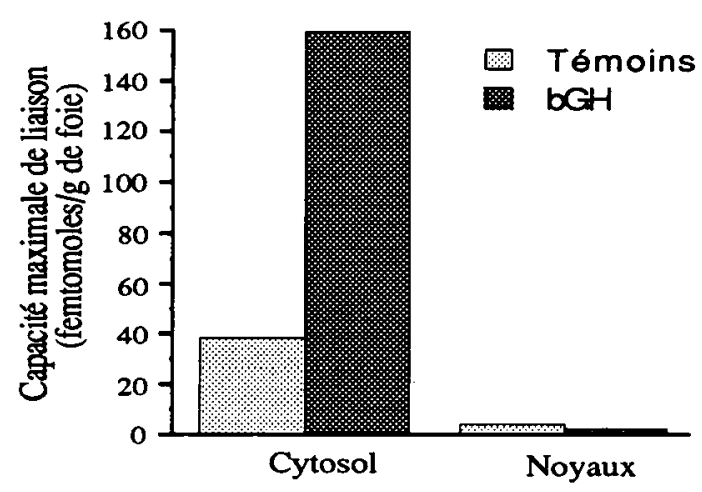

2ème Expérience

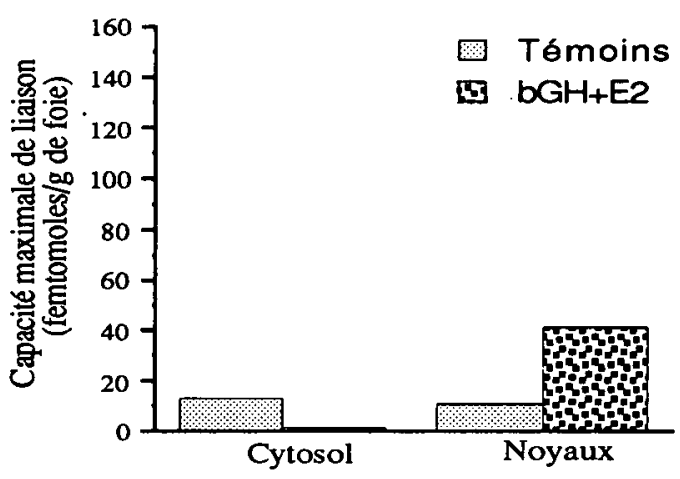

Figure 9 : Effet de l'hormone de croissance bovine (bGH) sur la capacité maximale de liaison de l'CEstradiol (E2) dans les fractions cytosolique et nucléaire préparées à partir de foie d'anguille argentée.

Les anguilles $(450 \pm 23 \mathrm{~g}-\mathrm{n}=6)$ reçoivent 3 injections par semaine d'hormone de croissance $(40 \mu \mathrm{g} \mathrm{bGH} / \mathrm{kg})$ pendant 3 semaines pour l'expérience 1 et deux semaines pour l'expérience 2. E2 $(500 \mu \mathrm{g} / \mathrm{kg})$ est injecté avec bGH une fois par semaine (Expérience 2). Les animaux sont sacrifiés 24 heures après la dernière injection. Les capacités maximales de liaison de l'œstradiol sont déterminées dans les fractions cytosolique et nucléaire préparées à partir des foies des 6 anguilles mises en expérience. Les coefficients de variation sont de 25 à $30 \%$ (MESSAOURIDEBOUN, 1994).

Figure 9 : Effect of bovine growth hormone (bGH) on the maximal binding capacity of Estradiol in the cytosolic and nuclear fractions prepared from the silver eel liver.

Eels $(450 \pm 23 \mathrm{~g}-n=6)$ received 3 injections per week of bGH $(40 \mu \mathrm{g} / \mathrm{kg})$ for 3 weeks in experiment 1 and 2 weeks in experiment 2. E2 $(500 \mu \mathrm{g} / \mathrm{kg})$ was injected once a week with bGH (exp.2). The maximal binding capacities were estimated in the cytosolic and nuclear fractions prepared from the 6 livers in each experimental batch. The variation coefficients were between 20 and $25 \%$ (MESSAOURIDEBOUN, 1994). 


\section{Conclusions}

L'induction de la synthèse des protéines vitellogéniques par le foie est plurihormonale :

- les stéroïdes ovariens jouent un rôle important sur le foie pour induire l'activation des gènes impliqués dans la synthèse des protéines vitellogéniques. L'œestradiol est actif sur ce processus à des doses pharmacologiques quand il est utilisé seul. Les androgènes pourraient jouer un rôle physiologique en modifiant le seuil de réponse de l'hépatocyte à E2. Ils sont en effet sécrétés immédiatement avant l'augmentation des teneurs en œstradiol.

- un rôle de l'hormone de croissance est mis en évidence dans ces processus de stimulation : la réponse vitellogénique apparaît pour des doses d'œstradiol 10 à 100 fois plus faibles en présence de GH. Elle agit en augmentant le nombre des récepteurs de l'œstradiol sous une forme activable par celui-ci.

\section{CONCLUSIONS GÉNÉRALES}

L'anguille européenne constitue un modèle particulièrement intéressant pour des études d'endocrinologie de la reproduction. Ceci est dû aux deux états physiologiques qu'elle présente dans les eaux douces continentales. Au stade jaune, le poisson se nourrit, la vitellogenèse n'a pas commencé et les ovaires sont, au sens strict, immatures. Les ovocytes sont au stade II pour lequel il n'est pas décrit de structure permettant l'endocytose de la vitellogénine. L'anguille jaune peut donc être considérée comme un témoin de “l'état zéro" de la vitellogenèse. Le passage vers le stade argenté est observable dans les eaux douces et induit des transformations importantes au niveau de l'ovaire qui acquiert les structures permettant l'endocytose de la vitellogénine. Au cours de l'argenture, l'anguille est un modèle à retenir pour l'étude des hormones hypophysaires intervenant dans ces processus précoces de la vitellogenèse.

L'utilisation de culture d'hépatocytes d' anguilles à ces deux différents stades de développement est un outil de choix pour rechercher les rôles des stéroïdes et, en particulier, celui des androgènes. Le rôle des androgènes dans l'induction hormonale de la vitellogenèse devra être précisé. Ces études pourraient porter.sur les mécanismes de stimulation du génome.

L'originalité des résultats présentés est soulignée par la mise en évidence du rôle de l'hormone de croissance. Elle agit en augmentant la sensibilité du foie à l'action de l'œstradiol. De même, chez l'anguille japonaise (Anguilla japonica), par des études in vitro sur des hépatocytes maintenus en culture primaire, KWON et al. (1994) ont aussi mis en évidence une action de la $\mathrm{GH}$ bovine en association avec l'œstradiol pour augmenter la réponse vitellogénique. Nous montrons, de plus, que cette action est à mettre en relation avec l'effet de la GH sur la synthèse des récepteurs hépatiques de l'œstradiol. Chez un amphibien (Rana esculenta ; CARNEVALI et al., 1992) ou chez un reptile (Chrysemys picta ; HO et al.,1985), l'hormone de croissance bovine joue également une rôle dans l'induction de la vitellogenèse. Cet effet est mis en relation, chez Rana esculenta, avec le cycle de reproduction à la période de recrudescence ovarienne, c'est-à-dire en prévitellogenèse (CARNEVALI et al., 1992). L'effet de la $\mathrm{GH}$ sur le foie pourrait être une action indirecte sur le métabolisme général. Cette hypothèse n'est pas à exclure et il sera nécessaire de rechercher si cette action est médiée par un facteur de croissance de type «insulin growth factor» (IGF).

Ces résultats offrent des perspectives de recherche fondamentale sur la localisation des récepteurs de l'œestradiol dans le cytoplasme ou dans le noyau. Chez l'anguille jaune, l'absence du ligand permettrait l'observation d'une localisation cytosolique beaucoup plus longue que chez d'autres Vertébrés.Un autre aspect concerne la composition du vitellus. Est-il, comme chez l'oiseau, constitué d'un composant apparenté au VLDL (STIFANI et al., 1990). Nous observons, en effet, que l'œstradiol augmente la synthèse des VLDL.

D'un point de vue appliqué, les différences dans la composition des apolipoprotéines des HDL mises en évidence au moment du jeun physiologique préparatoire à la migration de reproduction pourraient donner lieu à la réalisation d'un test d'argenture. Des possibilités d'analyse quantitative de l'argenture sont offertes par la mise au point d'un dosage immuno-enzymatique de type ELISA à l'aide des apolipoprotéines des HDL identifiées dans le sérum des anguilles jaunes. 


\section{REMERCIEMENTS}

Nous remercions le CSP pour son soutien financier qui a permis d'approfondir le travail sur les lipoprotéines plasmatiques.

\section{BIBLIOGRAPHIE}

BABIN P., 1987. Plasma lipoprotein and apolipoprotein distribution as a function of density in the rainbow trout (Salmo gairdneri). Biochem. J., 246, 425-429.

BABIN P., VERNIER J.M., 1989. Plasma lipoprotein in fish. Journal of Lipid Research, 30, 467-489.

BRADFORD M.M., 1976. A rapid and sensitive method for the quantification of microgram quantities of protein utilizing the principle of protein-dye binding. Anal. Biochem., 72, 248-254.

BURZAWA-GERARD E., DUMAS-VIDAL A., 1991. Effects of 17ß-estradiol and carp gonadotropin in normal and hypophysectomized European silver eel (Anguilla anguilla) employing a homologous radioimmunoassay for vitellogenin. Gen.Comp. Endocrinol., 84, 264-276.

BURZAWA-GERARD E., DELEVALLEE-FORTIER B., 1992. Implication de l'hormone de croissance au cours de l'induction expérimentale de la vitellogenèse par l'œstradiol17b chez l'anguille argentée femelle (Anguilla anguilla L.). C.R. Acad. Sci. PARIS, t.314, Série III, 411-416.

BURZAWA-GERARD E., NATH P., BALOCHE S., PEYON P., 1991. ELISA (Enzyme Linked Immunosorbent Assay) for vitellogenin and vitellus in the eel (Anguilla anguilla $L$.) and in the indian major carp (Labeo rohita).4th International Symposium on Reproductive Physiology. Norwich 7-12 July.

CARNEVALI O., MOSCONI G., YAMAMOTO K., KOBAYASHI T., KIKUYAMA S., POLZONETTI-MAGNY A. M., 1992. Hormonal control of in vitro vitellogenin synthesis in Rana esculenta liver : Effects of mammalian and amphibian growth hormone., Gen. Comp. Endocrinol., 88, 406-414.

CHAPMAN M. J., GOLDSTEIN S., MILLS G. L., LEGER C., 1978. Distribution and characterization of the serum lipoproteins and their apolipoproteins in the rainbow trout (Salmo gairdneri). Biochemistry., 17, 4455-4464.

FONTAINE M., 1975. Physiological mechanisms in the migration of marine and amphihaline fish. Adv. mar. Biol., 13, 241-355.

FONTAINE M., BERTRAND E., LOP.EZ E., CALLAMAND O., 1964. Sur la maturité des organes génitaux de l'anguille femelle (Anguilla anguilla L.) et l'émission spontanée des œufs en aquarium. C.R. Acad Sci., 259, 822-824.

FONTAINE Y.A., LOPEZ E., DELERUE-LEBELLE N., FONTAINE-BERTRANT E., LALLIER F., SALMON C., 1976. Stimulation gonadotrope de l'ovaire chez l'anguille (Anguilla anguilla L.) hypophysectomisée. Morphologie, activités adenylcyclase et phosphodiestérase de l'adenosine monophosphate cyclique. J. Physiol. Paris, 72, 871-892.

HO S. M., WANGH L.J., CALLARD I.P., 1985. Sexual differences in the in vitro induction of vitellogenesis in the turtle (Chrysemys picta) : role of the pituitary and growth hormone. Comp. Biochem. Physiol, 81B, 467-472.

KWON H. C., MUGIYA Y., 1994. Involvement of growth hormone and prolactin in the induction of vitellogenin synthesis in primary hepatocyte culture in the eel, Anguilla japonica. Gen. Comp. Endocrinol. 93, 51-60. 
LELOUP-HATEY J., HARDY A., NAHOUL K., QUERAT B., ZOHAR Y., 1988. Influence of a gonadotrophic treatment upon the ovarian steroidogenesis in European silver eel (Anguilla anguilla L.)., Les colloques de I'I.N.R.A., 4, 127-130.

LOPEZ E., FONTAINE Y.A., 1990. Stimulation hormonale in vivo, de l'ovaire d'anguille européenne au stade jaune. Reprod. Nutr. Dev., 30, 577-582.

MESSAOURI-DEBOUN H., BALOCHE S., LELOUP-HATEY J., 1991a. Characteristics and specificity of "putative" estradiol receptors in European eel (Anguilla anguilla L.). Gen. Comp. Endocrinol., 82, 240.

MESSAOURI-DEBOUN H., BALOCHE S., HARDY A., LELOUP-HATEY J., BURZAWAGERARD E., 1991b. Hepatic estradiol receptors and vitellogenesis in Anguilla anguilla $\mathrm{L}$. after treatment by estradiol alone or associated with bovine growth hormone. Gen. Comp. Endocrinol., 82, 238.

MESSAOURI-DEBOUN H., 1994. Les récepteurs de l'œstradiol chez l'anguille (Anguilla anguilla L.) : caractérisation et rôle dans l'induction hormonale au cours de la vitellogenèse. Thèse de doctorat de l'université de PARISVII, pp 1-132.

PEYON P., BALOCHE S., BURZAWA-GERARD E., 1993. Synthesis of vitellogenin by eel (Anguilla anguilla L.) hepatocytes in primary culture : requirement of $17 B$ - estradiolpriming. Gen. Comp. Endocrinol., 91, 318-329.

QUERAT B., HARDY A., LELOUP-HATEY J., 1985. Niveaux plasmatiques, vitesses de clearance métabolique et vitesses de sécrétion de la testostérone et de l'œstradiol173 chez l'anguille (Anguilla anguilla L.). Gen. Comp. Endocrinol., 59, 482-493.

SCATCHARD G., 1949. The attractions of proteins for small molecules and ions. Ann. N.Y. Acad. Sci., 51. 660-672.

SINHA H., JONES A.,1975. The European freshwater eel. $146 \mathrm{pp}$. Liverpool University Press G.B.

STIFANI S., BARBER D.L., NIMPF J., SCHEIDER W.J., 1990. A single chicken oocyte plasma membrane protein mediates uptake of very low density lipoprotein and vitellogenin. Proc. Natl. Acad. Sci. U.S.A., 87, 1955-1959. 